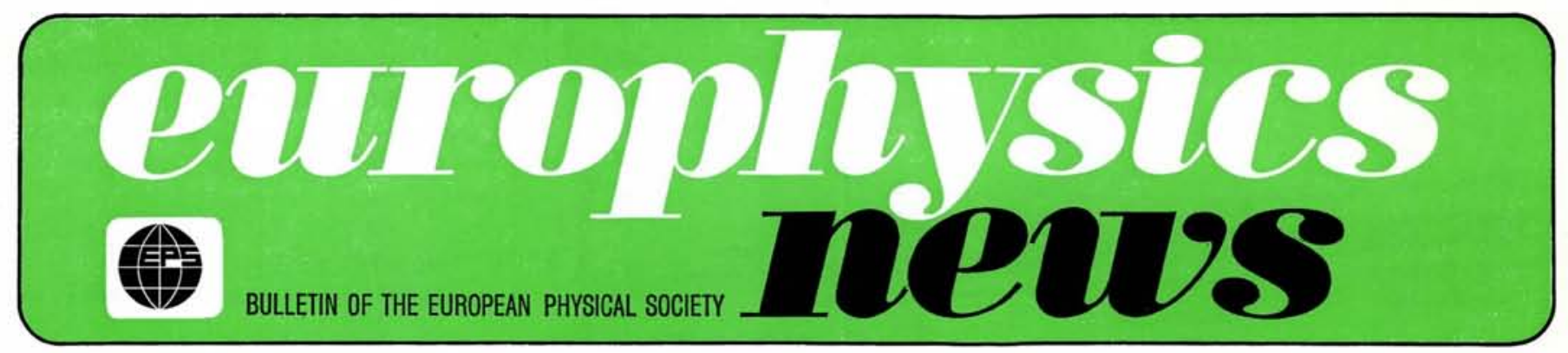

\section{The EPS in 1974}

\section{H.B.G. Casimir, President}

The European Physical Society can face the new year with confidence. True, we have had to reduce our expenditure, we shall have to postpone the realization of some of our bolder dreams, but we have put our house in order, the plans we now have are well within our possibilities and there is plenty of room for further initiatives.

At the Sinaia meeting of council the executive committee was instructed to take immediate and drastic measures to save the financial situation. At our latest council meeting at Geneva, on 27 and 28 November, the executive committee could report on a number of measures that had been taken and other proposals were approved.

In the following I shall briefly describe the new situation and also indicate its background, the way I see it.

\section{THE LOCATION}

\section{OF THE SECRETARIAT}

The secretariat will, for the time being, remain where it is, at PetitLancy. This is not particularly cheap, but we have been able to cut expense by subletting part of the premises. I think that all those who have been there, whether to take part in the committee meetings or just for private discussions, will agree that this home of the society is both simple and adequate. The location is pleasant and quiet, there are two good restaurants nearby, and even - if you reserve in time - a comfortable hotel.

Yet we are investigating at least one other possibility that may be even more advantageous. In any case I would be extremely reluctant to have EPS leave Geneva. Also I am convinced that a more or less permanent office, that does not change when the officers of the society change, is an important factor in establishing the identity of the society.

\section{THE POST OF THE EXECUTIVE SECRETARY}

From the first of January the post of executive secretary remains vacant. Everyone who is familiar with the affairs of EPS will know that Mrs. Etienne, who has filled this position from the beginning, has played a most important role in the development of the society, and to many of us it will be decidely unfamiliar to find her no longer in charge. Fortunately we have been able to make a new arrangement with her: she will remain in the picture, be it in another role; I come back to that presently. But the members will have to realize that the secretariat will no longer be able to provide guidance on general issues in the way it used to, although we are convinced that it will work smoothly from an administrative point of view. We believe that the principles of EPS are by now so well established that we can accept this situation, at least temporarily.

\section{THE OFFICE MANAGER}

The office is now in charge of the office manager Mr. G. Thomas. Mr. Thomas is a professional financial administrator, but he makes no claim to the title of physicist. All matters relating to membership, to fees, to divisional funds, etc. should be referred to $\mathrm{Mr}$. Thomas. As long as there is no executive secretary $\mathrm{Mr}$. Thomas will report directly to the secretary of EPS, Dr. Went, and it is to $\mathrm{Dr}$. Went that questions relating to physics and to the broader aims of EPS should be directed.

\section{THE SECRETARY}

It is obvious from the foregoing that the task of Dr. Went is a heavy one: he has not only to replace Dr. Laurens Jansen, he has also to do much of the work that was formerly done by the executive secretary. I should like to ask on his behalf for constructive assistance from all concerned.

\section{EUROPHYSICS NEWS}

The executive committee have decided to discontinue the employment of Mr. Crawford as from the first of January. During his rather short term of office Mr. Crawford put special emphasis on the social implications of science and some of our readers may even have felt that he overemphasized this aspect. But all of us have appreciated the wellwritten articles and interviews provided by Mr. Crawford himself, and we sincerely hope that he will from time to time be willing to contribute to these pages.

We are glad that we have found Mrs. Etienne willing to accept the position of editor on a half time basis. In this way her extensive knowledge of EPS and its history will continue to be a valuable asset to our society.

What kind of a publication should Europhysics News try to be? Also this question was discussed at the council meeting, on the basis of preliminary meetings of a smaller group. The following items were considered :

\section{Contents}

The EPS in 1974 . . . . 1

Society News . . . . . 4

Status of Thermonuclear Research . . . . . 6

Meetings . . . . . 8 


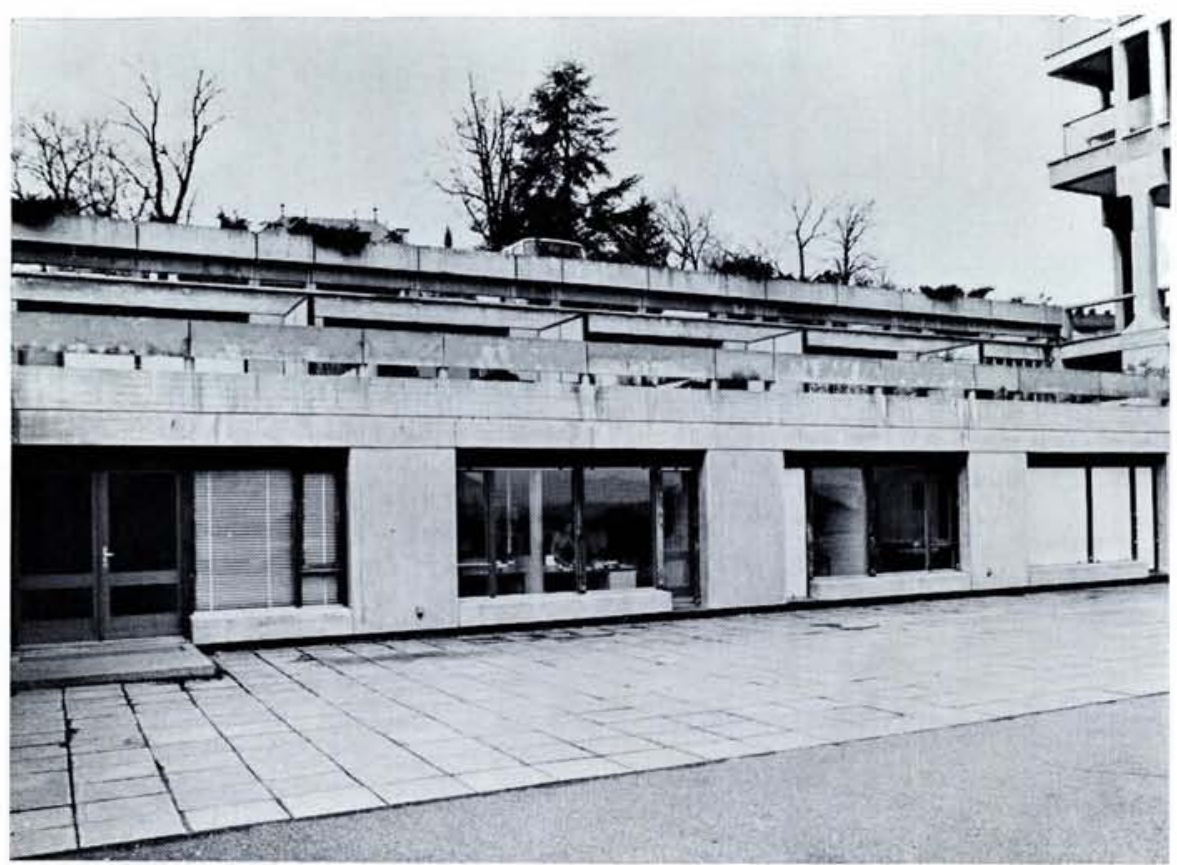

The Secretariat of the European Physical Society at Petit-Lancy.

\section{a) Review Articles}

The objection might be raised that there are many periodicals publishing such articles. But, if we look at the membership of EPS, we command such an enormous store of talent that it should in principle be easy to get articles of outstanding quality. Also, we should like to pay special attention to work in which European collaboration has been of significant importance.

\section{b) Recent Discoveries}

With due assistance from our members we ought to be able to publish very quickly exciting news from European laboratories.

\section{c) Conference Reports}

It was felt that these should emphasize one or two highlights rather than try to give a complete - and therefore necessarily somewhat superficial and colourless - enumeration of the whole program. Also it was believed that a frank and constructive criticism of the conference could be interesting and useful.

\section{d) Letters to the Editor}

The Europhysics News could become a useful forum for the discussion of numerous problems. Here, however, a word of warning is not out of place: we should avoid political discussions.

Most of us will have political views of one kind or another and several of us will even spend considerable time and effort in defending and promoting these views. This we can respect, but, if we want the EPS to survive as a society in which phy- sicists from countries with widely varying politic and economic systems take part, we must try to steer clear of discussions on the rights and wrongs of these systems. This is neither hypocrisy nor a curtailment of personal freedom; there is plenty of room for making known our opinions outside the EPS and outside Europhysics News. It is only too easy to break the rule I underlined: I may on occasion have done so myself. But, recognizing the role EPS has to play on the international scene of physics, it must be understood that on occasion the editor may have to reject a letter or a discussion because it is unsuitable for publication in Europhysics News on the grounds indicated.

\section{e) Society News}

Of course Europhysics News should also provide adequate information on the work of the society, on conferences, seminars, etc. This - and especially the meetings issue - is a humble but indispensable and in general appreciated activity.

\section{f) Divisional and Regional Correspondents}

We are now setting up a net of correspondents that can help to collar-sorry, what I should write is: who can assist in obtaining the collaboration of - prospective authors, dig up interisting news items and so on.

\section{g) Conference Abstracts}

Plans are now in an advanced state of preparation for arriving at a standardized form of publication of the abstracts of papers presented at
EPS conferences. This is not strictly a Europhysics News matter, but it is mentioned here because the project will be under the supervision of the editor.

\section{THE UNIT FEE \\ AND THE FINANCIAL SITUATION}

The proposal of the executive committee to increase the unit fee by $1 / 3$ was carried with a comfortable margin above the $75 \%$ of the votes cast that are required by the constitution. With the new scale of contributions we shall not only be able to have a balanced budget, we shall also be able to begin to pay off the debts we incurred during the first years of our existence. The raise may be considered as a compensation for inflation and if we look at it this way it must be recognized that it is only a partial and belated compensation : a regular "indexing" of the type that is usual in collective contracts between employees and employers would, over the years, have led to higher contributions. It is understandable that representatives from countries that, by the nature of their national economy, have been able to avoid inflation, voted against the proposal. This brings home to us the grim reality of the situation in Western Europe. If inflation continues EPS will five years from now again be forced to propose an increase and by that time our debts will not have been entirely repaid. (Here it is tempting to point out that graver difficulties than those of EPS will have to be faced by Western Europe, but a further discussion of that issue might get me dangerously close to the forbidden zone stipulated in 5. sub d) so I better drop this matter.)

The council strongly urged the executive committee to try to provoke a "miracle", that is, to try to obtain a one time subsidy to put us in the black. This is not an easy thing to do. No foundation, no governmental or international agency, no private benefactor will be inclined to pay debts incurred during former years. But one can also look at the situation in an entirely different way. Suppose that five years ago we had said : "We want to create a European Physical Society. It should bring together physicists from the Eastern and the Western European Countries, it should organize a large and comprehensive conference every three years, it should organize divisions that in turn organize conferences, seminars and summerschools, it 
should improve the mechanism of publication of papers on physics in Europe and contribute towards an internationally recognized unification of procedure between existing journals, it should publish a bulletin that gives not only information on coming events but that can also contribute to a discussion of the problems of physics and physicists... This we want to achieve in five years and after five years we shall be able to stand on our own legs. All we need is a starting capital of 200000 francs." I think that we would have had a very strong case. But now that we have achieved all this and more - and, obviously, find ourselves short of the starting capital - our chances for still obtaining this, much needed, subsidy are meagre. Suggestions are welcome.

\section{DIVISIONAL FUNDS}

In order to make clear that the situation is not one of unmitigated gloom it should be pointed out that the divisions (and, after all, much of the real work takes place under the auspices of the divisions) have in general been able not only to break even on their conferences and other activities, they have even been able to save up some money: they have, by now, a small working capital of their own. Since the divisions are not in the legal sense of the word corporate bodies (to put it in French : une division n'est pas une personne morale) they can strictly speaking not own property. Therefore the bulk of their balance finds itself in the EPS banking account at Geneva but it is strictly earmarked for each division, which can dispose of it for its own purposes (but of course in accordance with general rules and principles laid down by council and executive committee).

\section{THE CONFERENCE FUND AND THE CAPITATION-FEE}

It has been decided to create a conference fund. This is something entirely different from the divisional funds mentioned above. The Conference Fund will be directly available to the executive committee who can use it for the following purposes:

a) To provide a loan to a division in order to start a new venture (summer school or seminar for instance). Not all divisions have already collected sufficient capital to do this on their own in every case.

b) To pay for losses caused by unforseeable calamities. To take an extreme example, suppose that all preparations for a conference have been made, that a considerable amount of money has been spent, but that at the last moment the event has to be called off because an earthquake has completely destroyed the meeting place.

c) To provide travel-grants to physicists, and in particular to young physicists, who want to take part in EPS events. In the long run this should be the main purpose of the conference fund. It is hoped that we shall be able to make significant grants available for attending the next EPS general conference.

The conference fund will be formed by contributions from conferences, namely by imposing a capitation-fee (of one unit fee) on top of the participation-fee. In principle this capitation-fee will be levied for all EPS-organized conferences (Europhysics Conferences), but of course there may be cases, for instance small regional meetings where no participation-fee is imposed at all, where this is neither practicable nor desirable.

When the conference fund has attained the level of 25000 Swiss Francs the whole question will be reconsidered.

It should be emphasized that the conference fund should not be used for subsidizing conferences, and still less for defraying the costs of the central secretariat. If the secretariat has had to do more work in helping to organize a divisional conference than can be considered normal routine, then the secretariat will simply bill the division for services rendered.

\section{OTHER FEATURES \\ OF THE COUNCIL MEETING}

The meeting was held at CERN and I should like to express here once more our gratitude for the hospitality of that organization. Also, we should never forget that the primary concern of EPS should be physics, not organization of physics, and in this respect CERN was, of course, an outstandingly favourable meeting place. Most of the council members - with the exception of those, who, like the president, had to take part in special preparatory meetings - could join an excursion through CERN and found time for private discussions with old and new friends. On Tuesday afternoon C.M. Braams gave a timely and illuminating lecture on the state of fusion research. This lecture was
New Books from North-Holland

\section{Principles of Quantum Mechanics}

\section{The Non-Relativistic Theory with some illustrative applications}

By W.V. HOUSTON $\uparrow$ and G.C. PHILLIPS, William Marsh Rice University, Houston, Texas.

1973. 388 pages.

Dfl. 110.00 (about US \$ 44.00)

CONTENTS: Experimental necessity for quantum mechanics. Analysis of classical mechanics. Formulation of wave mechanics. Characteristic states or eigenstates. The classical approximation. Motion of a particle in a central field. Methods of approximation. A generai gur gular momentum and spin. Systems tromagnetic radiation in empty space. interion refice Hydron-like spectra. Two electron spectra spectra. Quantum mechanical scattering Quantum scitering in solids.

\section{Progress in Optics, volume $\mathbf{X I}$}

Edited by E. WOLF, University of Rochester, New York.

1973. 372 pages.

Dfl. 100.00 (about US $\$ \mathbf{4 0 . 0 0 )}$

CONTENTS: Master equation methods in quantum optics. Recent developments in far infrared spectroscopic techniques. Interaction of light and acoustic surface waves. Evanescent waves in optica imaging. Production of electron probes tonian theory of beam mode propagation. Gradient index lenses.

\section{The Chemistry of Imperfect Crystals 2nd Revised Edition}

Volume I: Preparation, Purification, Crystal Growth and Phase Theory.

By F.A. KROGER, University of Southern California, Los Angeles.

1973. 328 pages.

Dfl. 70.00 (about US \$ 28.00)

CONTENTS : Preparation of materials purification, analysis, crystal growth and doping. Phase theory : graphical representation. Thermodynamics of phase relations: general remarks: the gross approach. Detailed description of gaseous and liquid phases: the molecular approach. Thermodynamics of phase relations: the microscopic approach. Reac tions between condensed phases and vapour in open systems.

\section{NORTH HOLLAND}

P. O. Box 211

Amsterdam - The Netherlands

Sole distributors for the U.S.A. and Canada :

American Elsevier Publishing Company 52 Vanderbilt Ave. New York, NY 10017 
also attended by many members of the CERN staff.

\section{NEXT GENERAL CONFERENCE}

It has now been decided that the next general conference will take place at Bucharest, Romania, during the second week of September 1975. Although the details of the program have still to be worked out, the general idea is to take Energy, its nature, its various manifestations, its transformations as a central theme. The objection has been raised that this is now a very fashionable and almost hackneyed theme, and that it is somewhat doubtful whether physicists can add something useful to what is now being discussed by engineers, economists, ecologists and politicians. Personally I am of opinion that such criticism is entirely unfounded. Energy is a notion created by physicists, and in a period when others are hectically discussing the mundane implications of the more trivial aspects of this notion, it is only fitting that physicists should refilect once more on its fundamental meaning. Such reflections should comprise energy in general relativity and in cosmology as well as in field theories and particle physics. They should deal with statistical mechanics and the second law of thermodynamics, but also with progress in the theory of the chemical bond and of the energy-bands in solids, or in our knowledge and understanding of nuclear reactions and nuclear energy-levels. The subject gives also opportunity for historical and didactical contributions and for digressions into, for instance, the field of fundamental biology. But I better stop here, lest I anticipate too much on the work of the program committee.

I am afraid that this is not a very inspired or inspiring New Year's message : for that an enumeration of a number of administrative details is hardly the best vehicle. Yet, while writing, I became more and more confident about the future of EPS. I felt that EPS has already done something significant, and will be able to do much more, for the physicists in Europe. And thinking of the physicists of Europe, with their hopes and ambitions, with their struggles and frustrations, but also with their successes and achievements, I realized that all of us are united by the love for our beautiful discipline, and by the joy of discovery and of understanding.

A happy New Year to all of you!

\section{Society News}

\section{Divisions and Sections}

The newly elected Board of the Atomic Physics Division chose A.H. Gabriel, Abingdon, as its new chairman to succeed $\mathrm{H}$. van Regemorter, Paris.

Call for nominations. The six Sections committees of the Condensed Matter Division will be renewed this year, i.e.: Liquid and Amorphous Materials Section, Low Temperature Physics Section, Magnetism Section, Metals Section, Macromolecular Physics Section, Semiconductors and Insulators Section.

The existing committees of the Sections are preparing a list of candidates.

Members of the Sections can make proposals for candidates ( 6 signatures or 6 names are necessary in order to propose a candidate).

Please send your proposals for candidates before 30 March 1974 to:

\section{A. Libchaber}

Secretary, Condensed Matter Division Ecole Normale Supérieure

24, rue Lhomond

F - 75231 Paris 05.

The new Campus of the Flemish University of Leuven (Belgium) will be the site, in 1975, of one of the first "intersectional" Europhysics Conferences. At the meeting of the Board of the Condensed Matter Division - in Paris on 23 June 1973 - three Sections of the Division, the Magnetism Section, the Metals Section and the Semiconductors and Insulators Section proposed to organize a Europhysics Conference on Electronic Properties of Solids under High Pressure. Cosponsor of this conference would be the European High Pressure Research Group, which is "affiliated" to the Condensed Matter Division of EPS.

The Conference will be held in Leuven from 1 to 5 September 1975 , and will be organized jointly by the two Solid State Laboratories in the Physics Department of the University, the Laboratorium voor Vaste StofFysica en Magnetisme and the Laboratorium voor Vaste Stof- en Hoge Druk-Fysica. Local organizers are
Professor O. Verbeke and Professor L. van Gerven.

Topics of the meeting are :

- Magnetic properties under high pressure

- Electronic phase transitions under high pressure

- Mott transitions

- Band structure properties under high pressure

- Semiconductors under high pressure

- Superconductors under high pressure

- Megagauss fields.

\section{Europhysics Journals}

Starting in January 1974, the Journal de Physique will include a letters section. This has been made possible by its new periodicity of 11 issues a year. Topics treated in letters will cover not only the field of the Journal de Physique, but also that of the Revue de Physique Appliquée (new experimental data, instrumentation). Letters may be either self-contained communications or brief accounts of extensive work; in the latter case, authors should indicate when and how they intend to publish the detailed article implied by their letter.

There will be no proof reading. Reprints will be available, the first 50 free of charge.

Letters should not exceed the length of 4 printed pages. As an indication, each page contains 2 columns of 50 lines, each line contains 50 characters or spaces; a figure $10 \mathrm{~cm}$ high $\times 8 \mathrm{~cm}$ wide (one-column width) takes 25 lines, a simple formula 3 to 7 lines; the title, author's name and abstracts take about $1 / 3$ page. English, French and German are accepted. Letters should have two abstracts, one in English and one in French, not exceeding 75 words each. The presentation should follow the rules of the Europhysics Style Manual (available at the European Physical Society, and published in the Journal de Physique, January 1973). 